\title{
Carotid Stenosis under Strontium Ranelate
}

\author{
Kawtar Nassar ${ }^{1 *}$ and Saadia Janani ${ }^{2}$ \\ ${ }^{1}$ Department of Rheumatology, Ibn Rochd University Hospital Center, Morocco \\ ${ }^{2}$ Department Chief of rheumatology at University Hospital Center, Morocco
}

*Corresponding author: Kawtar Nassar, Rheumatology Department, Ibn Rochd University Hospital Center, Faculty of Medicine and Pharmacy of Casablanca, Hassan II Morocco, Morocco.

To Cite This Article: Kawtar Nassar, Saadia Janani, Carotid Stenosis under Strontium Ranelate. Am J Biomed Sci \& Res. 2021 - 11(4). AJBSR. MS.ID.001658. DOI: 10.34297/AJBSR.2021.11.001658.

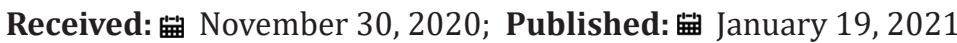

\begin{abstract}
Strontium ranelate (RS) occupies a place in the therapeutic arsenal of osteoporosis. It has been granted Marketing Authorization (MA) for the treatment of postmenopausal osteoporosis since January 2006. Its anti-fracture efficacy is at least equal to that of bisphosphonates. If some side effects are frequent and not severe, the serious risks of venous thromboembolism and DRESS are less frequent. Arterial accidents are exceptional. We report a case of internal carotid artery stenosis that occurred three years after treatment with strontium ranelate in a 76-year-old woman treated for non-active rheumatoid arthritis. Indeed in view of the side effects, RS was suspended.
\end{abstract}

Keywords: Thromboembolic accidents; strontium ranelate; osteoporosis

\section{Introduction}

Osteoporosis is a generalized skeletal disorder characterized by low bone mass and deterioration of the microarchitecture of bone tissue, leading to bone fragility. In Morocco, it is estimated that 35\% of women over the age of 50 are osteoporotic. Its gravity is the risk of fracture. Stontium Ranelate (RS) has been marketed in Morocco since 2007. It is involved in reducing the risk of vertebral fractures and hip fractures. Given its tolerance, it is mainly indicated, apart from male osteoporosis, in case of allergy or contraindications to bisphosphonates. However, pharmacoepidemiological studies and pharmacovigilance data confirmed the risk of venous thromboembolic events, including pulmonary embolism, and DRESS-type severe hypersensitivity syndrome. On the other hand, arterial accidents are exceptionally encountered. We report a case.

\section{Clinical Case}

Mrs. E.L, aged 76, has been followed since 2004 for rheumatoid arthritis, which is seropositive, deforming and destructive, initially refractory to the various anti-rhumatoid arthritis conventional treatment (methotrexate,salazopyrine), she has been under
Leflunomide since 2009. No previous intake of corticosteroids was noted. In its (We note in her past medical history maybe) antecedents, postmenopausal osteoporosis, non-fractured, lumbar and femoral, she was treated since 2009 by strontium ranelate $(2 \mathrm{~g}$ per day), with good compliance and initial therapeutic tolerance. The clinical examination at the follow-up found a patient who weighed $56 \mathrm{~kg}$. The body mass index was 22.2. The blood pressure was 13 / $07 \mathrm{cmHg}$. The cervical examination revealed a left-lateral cervical swelling, evolving for six weeks which caused pain on palpation, associated with supraclavicular edema. There was no alteration of the general condition or fever. The otorhinolaryngological examination had not revealed lymphadenopathies. The parotids, tonsils, thyroids, dental examinations were without abnormalities. There was no hepatomegaly, splenomegaly, jugular vein turgor, or collateral circulation. Doppler ultrasound of the jugulo-carotidian axes demonstrated $75 \%$ left internal carotid stenosis and right internal carotid thrombosis from its origin with a very damped flow (Figures $1 \& 2$ ). The laboratory tests revealed no dyslipidemia or inflammatory syndrome, the sedimentation rate was $25 \mathrm{~mm}$ 
/ $1^{\text {st }}$ hour, the C-reactive protein $8 \mathrm{mg} / \mathrm{l}$, the composite activity index of rheumatoid arthritis (DAS 28) was at 2.69. The hemogram, hemostasis exploration balance, and electrophoresis of plasma proteins were normal. The rest of the metabolic exploration checkup, especially the blood sugar was correct. The drug origin of the thrombosis required discontinuation of strontium Ranelate. The patient was placed on unfractionated heparin and platelet antiaggregant, with close monitoring. The clinical course was good (disappearance of the cervical swelling), the ultrasound control was normal, with receding at 25 months.
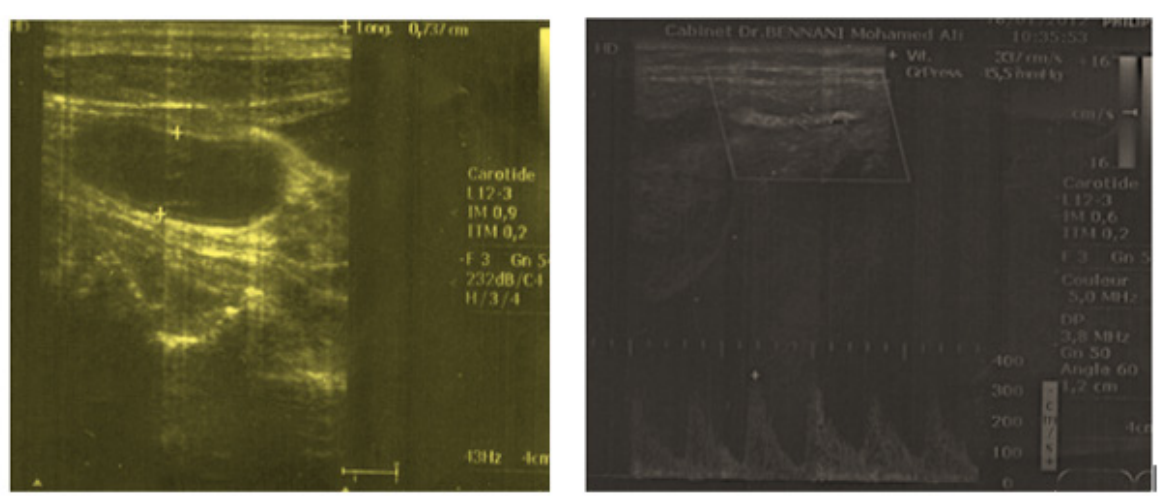

Figures 1 \& 2: Echodoppler of the jugulo-carotidian axes: Stenosis of the left internal carotid artery of $75 \%$ and right carotid thrombosis from its origin with very damped flows.

\section{Discussion}

Strontium Ranelate is composed of 2 stable strontium atoms and ranelate salt. It is the only anti-osteoporotic agent capable of positivering bone balance and at remodeling sites by combining bone formation and reduction of osteoclastic resorption [1]. It is indicated in postmenopausal osteoporosis [2], and in the prevention or recurrence of fractures [3,4]. It represents a therapeutic alternative in case of contraindication or intolerance to bisphosphonates [5,6]. Nevertheless, some adverse effects are attributed to treatment, the risk of venous thromboembolism and DRESS (being) which was the most severe. The annual incidence reported in the regional pharmacovigilance center registry is $2.7 \%$ with strontium ranelate versus, $1.9 \%$ with placebo, and a relative risk of 1.42 [7]. A French study showed that venous thromboembolic events (VTEA) were the main cardiovascular adverse events (93/104) with an incidence at 1/31 052 months of treatment, with deep vein thrombosis (54\%), embolism pulmonary (34\%), and $2 \%$ thrombosis of the central vein of the retina. At least one risk factor for venous thrombosis was found in $28 \%$ of patients [5]. In the same study, $6 \%$ of cerebrovascular accidents and transient ischemic attacks, and 1\% of central retinal artery thrombosis were reported. A cohort of English general practitioners [8] attributed cardiovascular risk to older age, and osteoporosis rather than to RS. The relative risk of stroke was 1.75 in untreated osteoporotic women as in non-osteoporotic women, with a similar risk under Alendronate. This risk also existed with raloxifene and bisphosphonates in a Danish cohort [9] and in randomized, observational studies [10]. Additional biochemical studies aimed at investigating the relationship between thromboembolic risk and
SR which did not show any changes in the biological parameters of hemostasis before and after two months of treatment $[11,12]$. In addition, a study in 45 patients treated for three months with RS found a decrease in the concentration of homocysteine [13].

The French Health Products Safety Agency (AFSSAPS) and the Moroccan Poison Control and Pharmacovigilance Center had issued a warning regarding the use of SR. The Transparency Committee reevaluated this medicine on May 11, 2011 and 2014. Its benefit-risk ratio was considered medium, and the indication was restricted to patients under 80 years old, not immobilized with contraindication / intolerance to bisphosphonates, without risk factors for venous thromboembolism (VTE) [14]. Our patient illustrates a rare and particular complication of carotid thrombosis occurring under Strontium Ranelate. She is not sedentary or overweight. She has no dyslipidemia, and her rheumatoid arthritis was not active. There was also no corticotherapy. Nevertheless, there were certain limits: Presence of added risk factors for vascular thrombosis was found in our patient: advanced age, rheumatoid arthritis. This does not allow us to formally link the cause of carotid stenosis to this antiosteoporotic therapeutic family. This is, to our knowledge, the first Moroccan observation.

We report our observation, considering a probable carotid origin of the reported cases of arterial accidents (AVC and AIT) under strontium ranelate. These risks must be taken into account in the benefit-risk balance of strontium ranelate.

\section{Conclusion}

Although it occupies a place in the therapeutic arsenal of osteoporosis, with an efficiency close to that of bisphosphonates, 
venous thromboembolic side effects and probably arterial strontium ranelate accidents can be life-threatening. The physiopathogenic link is still heterogeneous. The rationalization of its prescription and regular monitoring of patients is essential. In the future, we hope that epidemiological studies may lead to comprehensive data analyzes on adverse effects under the latter.

\section{Conflicts of Interest}

None.

\section{References}

1. Pierre J Meunier (2006) Strontium ranelate. Revue du Rhumatisme 73: 834-837.

2. Reginster JY, Deroisy R, Dougados M, Juspin I, Colette J, et al. (2002) Prevention of early postmenopausal bone loss by strontium ranelate: a randomized, two-year, double blind, dose-ranging, placebo-controlled trial. Osteoporos Int 13(12): 925-931.

3. Meunier PJ, Roux C, Seeman E, Ortolani S, Badurski JE, et al. (2004) The effects of strontium ranelate on the risk of vertebral fracture in women with postmenopausal osteoporosis. N Engl J Med 350(5): 459-468.

4. Reginster JY, Seeman E, DeVernejoul MC, Adami S, Compston J, et al (2005) Strontium ranelate reduces the risk of non-vertebral fractures in postmenopausal women with osteoporosis: treatment of peripheral osteoporosis (Tropos study). J Clin Endocrinol Metab 90(5): 2816-2822.

5. Annie-Pierre Jonville-Bera, Elisabeth Autret-Leca (2011) Ranélate de strontium (Protelos) : Effets indésirables rapportés en France. Article original. Presse Med 40(10): e453-e462.
6. IGAS (2011) Rapport sur la pharmacovigilance et gouvernance de la chaîne du médicament. Rapport IGAS no RM. Pp.209.

7. Chaabane A, Aouam K, Ben Fredj N, Boughattas NA (2010) DRESS syndrome : étude de 11 cas et revue de la littérature. Therapie 65(6): 443-450.

8. Breart G, Cooper C, Meyer O, Speirs C, Deltour N, et al. (2010) Osteoporosis and venous thromboembolisme: a retrospective cohort study in the UK General Practice Research Database. Osteoporos Int 21(7): 1181-1187.

9. Vestergaard P, Schwartz K (2010) Department of Endocrinology and Metabolism C, Aarhus Univrsity Hospital. Osteoporos Int. 21(9): 15911597.

10. Halil M, Cankurtaran M, Yavuz BB, Ulger Z, Piskinpasa S, et al. (2007) Short-term hemostatic safety of strontium ranelate treatment in elderly women with osteoporosis. Ann Pharmacother 41(1): 41-45.

11. Grosso A, Douglas I, Hingorani A, MacAllister R, Smeeth L (2008) Postmarketing assessment of the safety of strontium ranelate; a novel caseonly approach to the early detection of adverse drug reactions. Br J Clin Pharmacol 66(5): 689-694.

12. Ulger Z, Guret EI, Halil M, Oozen G, Kalan I, et al. (2012) Hemorheological changes with strontium ranelate treatment do not seem to be related to its claimed prothrombotic effects. Arch Gerontol Geriatr 54(1): 218-221.

13. Bayhan I, Uygur D, Ugurlu N, Ozaksit G (2009) Strontium ranelate decreases plasma homocysteine levels in postmenopausal osteoporotic women. Rheumatol Int 29(3): 263-266.

14. (2011) Avis de la Commission Nationale de Pharmacovigilance du 27 Septembre 2011 sur les données de sécurité du Protelos. 